\title{
Characterizing Land Use Impacts on Functional Plant Diversity for Life Cycle Assessments
}

\author{
Laura Scherer,* Sven A. van Baren, and Peter M. van Bodegom
}

Cite This: Environ. Sci. Technol. 2020, 54, 6486-6495

Read Online

ABSTRACT: Decision support tools such as life cycle assessment (LCA) increasingly aim to account for impacts on biodiversity. While taxonomic measures like species richness have been implemented, they do not fully grasp the impacts on ecosystem functioning. Functional diversity, derived from the species' traits, is more representative of ecosystem processes. This study provides a framework for developing characterization factors for functional diversity as affected by land use. It exploits the large databases on plant traits and species composition that have recently become available and allow bringing biodiversity impact assessment to the next level. Three functional diversity indices therein describe different aspects of functional diversity, namely richness, evenness, and divergence. Applying our framework to Germany as a proof of

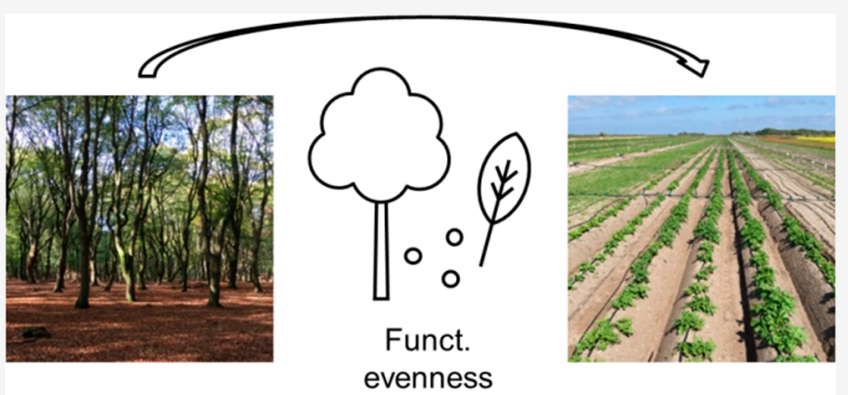

Funct.

richness concept, we show significant losses in functional plant diversity when converting natural forests to agricultural land use. Consistently across different forests and agricultural systems, functional richness decreases steeply and functional divergence moderately upon occupation. In contrast, functional evenness exhibits opposite trends. The resulting characterization factors are likely to be representative of temperate regions. The framework is flexible and applicable to larger scales and other impact categories. As such, it facilitates harmonizing biodiversity impact assessments and better represents ecosystem functioning by incorporating functional diversity.

\section{INTRODUCTION}

The Intergovernmental Science-Policy Platform on Biodiversity and Ecosystem Services (IPBES) highlighted the importance of biodiversity and the severity of its loss in their recent "global assessment of biodiversity and ecosystem services". Biodiversity is not only vital for ecosystem functioning but also for human well-being. However, it is declining faster than ever in human history. The largest direct driver of the loss of terrestrial and freshwater biodiversity is land use, especially due to agriculture. ${ }^{1}$ Despite abatement efforts, no improvement in biodiversity decline has been achieved yet. $^{2}$ Across most of the world's land surface, biodiversity loss has already transgressed the proposed planetary boundary. ${ }^{3}$ This highlights the urgency to safeguard biodiversity and to make better-informed decisions based on scientific evidence.

Life cycle assessment (LCA) is a tool to quantify environmental impacts ${ }^{4}$ and can support decision-making to protect biodiversity. It takes a systems perspective, and compiles inputs (resources) and outputs (emissions) of a product system throughout its life cycle. In the life cycle impact assessment (LCIA) phase, these inputs and outputs are translated to common impact units for impact categories or areas of protection through characterization factors. ${ }^{4}$ For example, impacts of land use (as an input) on ecosystem quality (as an area of protection) can thus be quantified.

Various LCIA methods exist to characterize the impacts of land use on ecosystem quality. ${ }^{5}$ They cover, for example, net primary production, ${ }^{6}$ hemeroby (naturalness), ${ }^{7}$ and most often species richness ${ }^{8}$ as indicators of ecosystem quality. While species richness is merely a count of species, functional diversity considers the functional traits of a species and more strongly relates to ecosystem functioning than species richness. ${ }^{9}$ The LCA community recognizes the value of functional diversity and recommends it as a complementary metric. ${ }^{10}$ However, to date, there is only a single LCIA method that uses functional diversity: Souza et al. ${ }^{11}$ proposed characterization factors for land use impacts on the functional diversity of mammals, birds, and plants in the Americas. They based their characterization factors on existing meta-analyses and used Petchey and Gaston's index ${ }^{12}$ to describe functional

Received: November 28, 2019

Revised: March 23, 2020

Accepted: April 28, 2020

Published: April 28, 2020

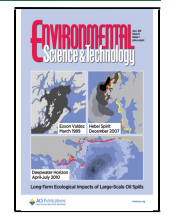




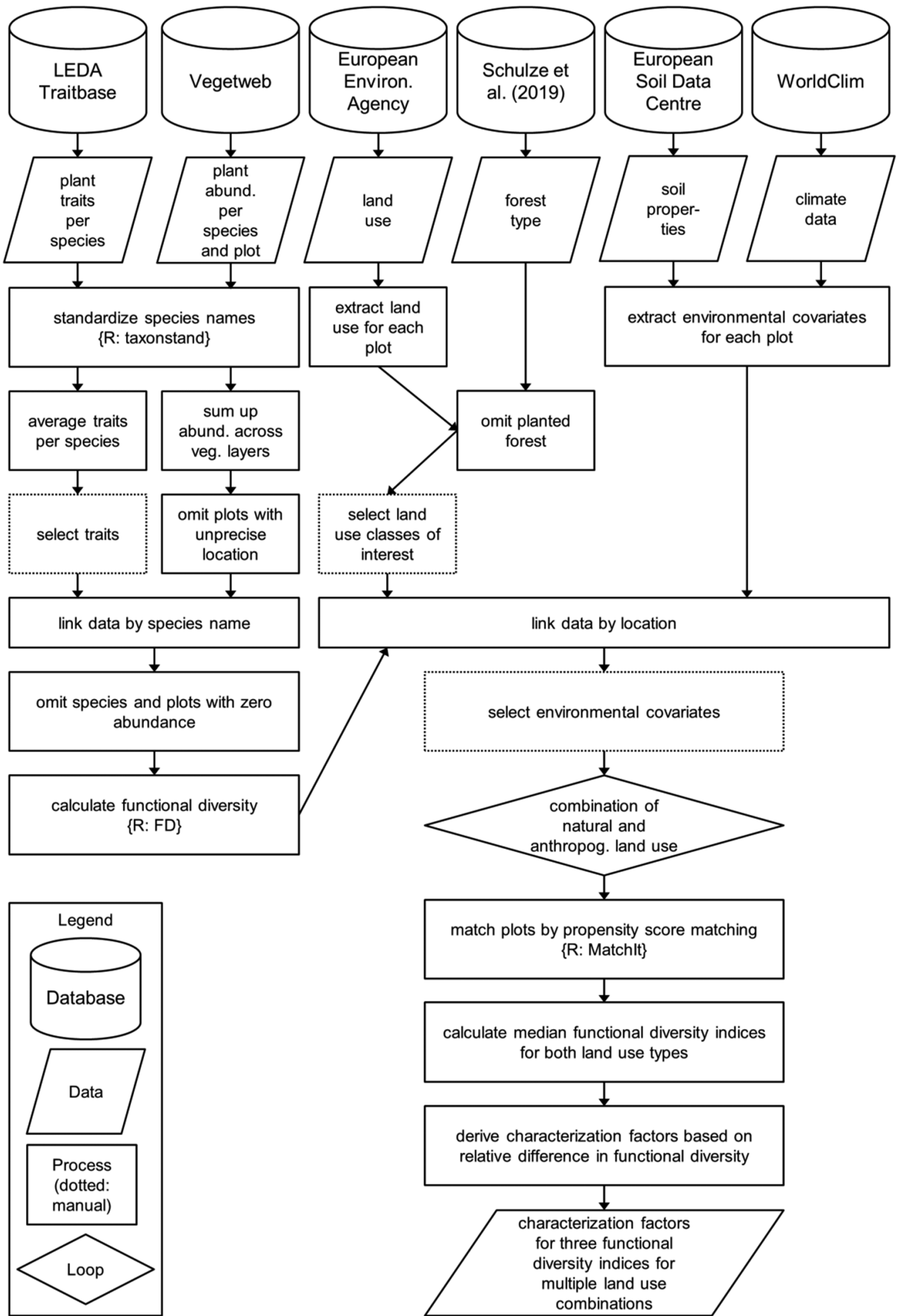

Figure 1. Conceptual framework for the derivation of characterization factors for functional diversity.

diversity. The index measures functional richness, a specific component of functional diversity, by means of a functional dendrogram. Their results show significant differences in characterizations factors for species richness and functional richness, including in a comparison for plants.

Ahmed et al. ${ }^{13}$ recommended considering three independent and complementary components of functional diversity: richness, evenness, and divergence. Mason et al. ${ }^{14}$ define functional richness as the amount of functional niche space filled by species. It relates to the range of resources used and thus to productivity, environmental tolerances, and invasion resistance. Functional evenness describes the regularity of the abundance distribution within the filled space. It relates to over- or underutilization of resources, and is hence an early warning signal of changes in community composition. Functional divergence is the degree to which the abundance distribution within the filled space maximizes differences in the functional characters within the community. It relates to niche 
differentiation and thus resource competition. ${ }^{14}$ Frameworks to include all three metrics for defining biodiversity impacts have not yet been developed.

The increasing availability of data sets on species composition, ${ }^{15}$ species traits, ${ }^{16}$ and global trait patterns ${ }^{17}$ allow a much more detailed understanding of functional diversity patterns than feasible a few years ago. Exploiting datadriven approaches making use of such rich ecological resources-if combined with ecological concepts-provides new venues for more realistic impact assessments.

This study pursues two research objectives. First, it aims to develop characterization factors for land use impacts on functional plant diversity. Second, it provides a proof of concept, applied to Germany, for using a data-driven approach to develop characterization factors covering all three recommended indices of functional diversity.

\section{MATERIALS AND METHODS}

Characterization factors were derived for functional plant diversity loss caused by marginal land occupation of former forests with agricultural land, taking into account confounding environmental covariates (Figure 1).

Functional Plant Diversity. Functional diversity metrics express the diversity in (functional) traits, often weighing contributions of traits of individual species by their abundance. Hence, functional diversity estimates depend on both the identity of traits included as well as the number of traits. Conceptually, plant traits fall into three functional categories: persistence, regeneration, and dispersal. ${ }^{18}$ To cover all relevant aspects concerning ecosystem functioning, trait selection should ideally cover all the categories. Due to data limitations and the demand for complete trait sets by species, the number of traits included in an analysis is commonly constrained to a few key representative traits.

Traits were obtained from the most comprehensive trait database for Northwest Europe, including Germany, the LEDA Traitbase. ${ }^{18,19}$ LEDA provides 26 traits for up to 3345 species. Trait selection was based on the species coverage per trait, the association among traits, and the functional category. As in most studies, only plant traits with continuous values (e.g., canopy height in $\mathrm{m}$ ) were included in the analysis, as they better capture the interspecific variation than categorical traits (e.g., dispersal type like meteorochor-by wind, zoochor-by animals, etc.). ${ }^{20}$ To maximally span the trait space, only traits with absolute pairwise Spearman correlation coefficients below 0.5 were included. ${ }^{21,22}$ In the final selection of four traitscanopy height, specific leaf area, seed number, and seed mass-absolute correlations ranged from 0.002 to 0.371 (Supporting Information (SI) Table S1). Canopy height and specific leaf area relate to the persistence of a plant species. Specific leaf area is especially well studied ${ }^{23}$ and hardly correlates with other traits. As such, it adds a distinct characteristic to the trait spectrum. Seed number and seed mass are relevant to regeneration. They correlate only moderately with canopy height and among each other. None of the selected traits belongs to the functional category dispersal. The only continuous dispersal-related trait with sufficient species coverage is the seed release height. However, since it strongly correlates with canopy height but covers fewer species, it was omitted. Overall, the four selected traits are all available for 1257 plant species.

Vegetweb, the German database of vegetation plots, provides georeferenced data on plant abundance for plots with complete lists of 1684 species. $^{24,25}$ The full data set contains over 125000 plots, spanning the period from 1922 to 2017. For the scope of this study, only freely available data was used (SI Figure S1) and the individual projects are listed in the Supporting Information. The temporal coverage was limited to 1998-2017 to avoid the use of older data with a larger gap between vegetation and land use monitoring. These two restrictions reduced the data set to a subset of 5215 plots distributed throughout Germany. Species abundance, as mean cover percentage, was determined by summing abundances across the multiple vegetation layers present in Vegetweb. The mode of the plot size is $4 \mathrm{~m}^{2}$, and its median is $6 \mathrm{~m}^{2}$. Since some aspects of functional diversity, including functional richness and evenness, depend on the plot size, ${ }^{26}$ plots with an area exceeding $100 \mathrm{~m}^{2}(8.99 \%)$ were omitted. Plots with an unknown area $(6.77 \%)$ were assumed to be smaller than 100 $\mathrm{m}^{2}$ and included. Vegetweb indicates the location of plots in one of three forms: two coordinate reference systems and an old German topographic map series at a scale of 1:25000 called "Messtischblatt". Plots with locations given in the topographic map series were considered as too unprecise and omitted (23.2\%). Overall, 4007 plots remained for analysis.

The plant trait and abundance data were matched based on species names after standardizing all species names with the $\mathrm{R}$ package taxonstand ${ }^{27}$ version 2.2 that uses The Plant List (http://www.theplantlist.org). The matching resulted in 860 species occurring in both databases. After removing species and plots with zero abundance, remaining plots had trait values known for, on average, $74.4 \%$ of the species present in a plot.

The three functional diversity metrics-functional richness, evenness, and divergence-were selected based on Ahmed et al. ${ }^{13}$ and calculated following Villéger et al. $^{28}$ These indices apply to multiple traits and are complementary and independent of each other. Functional richness is measured by the convex hull volume of the filled functional space. Functional evenness is based on the minimum spanning tree linking all the species and species abundance. Functional divergence is estimated by the abundance-weighted distance from the center of gravity in the functional space. ${ }^{28}$ The function $\mathrm{dbFD}$ of the $\mathrm{R}$ package $\mathrm{FD}^{29}$ version 1.0.12 includes, among others, generalized algorithms for the three indices proposed by Villéger et al. ${ }^{28}$ All traits were standardized to an average of zero and unit variance (stand. $x=$ TRUE). Villéger et $\mathrm{al}^{28}$ suggest doing so to avoid any influence of the units of measurement and to equally weigh all traits, as the relative importance of different traits is rarely known. In addition, functional richness was normalized to the "global" functional richness of all species (stand.FRic $=$ TRUE). In doing so, all three indices are constrained between 0 and 1 . The indices are derived from the distances between species within the functional trait space, which is represented by the speciestrait matrix. Laliberté and Legendre ${ }^{29}$ generalized the metric set by Villéger et $\mathrm{al}^{28}$ in their R package FD by allowing for different distance measures and by using principal coordinate analysis (PCoA) axes as traits for calculating functional diversity. Since the species-trait matrix in this study only contains continuous, unweighted traits and excludes species with missing trait values, the Euclidian distance was used. The minimum number of species per plot was set to three, which is lower than the number of selected traits (four). The (two) PCoA axes represented, on average, $63 \%$ of the variation in the traits. 
Land Use. The land use of vegetation plots was retrieved from the CORINE Land Cover (CLC) data sets. ${ }^{30}$ CLC is coordinated by the European Environment Agency, and their maps cover Europe. The data is in vector format. Its minimum mapping unit is 25 ha and its minimum width of linear elements is $100 \mathrm{~m}$. It provides information on 44 land use classes, and 17 overlap with the preprocessed vegetation plots (SI Table S2). Maps are available for the years 1990, 2000, 2006, 2012, and 2018. The year the vegetation data was collected was used to assign the CLC map closest to that year.

Six land use classes were chosen for further analysis based on the number of vegetation plots they cover (SI Table S2). They include three forest types representing natural land use (broadleaved forest, coniferous forest, and mixed forest) and three agricultural land use types representing anthropogenic land use (nonirrigated arable land, pastures, and complex cultivation patterns). The class "land principally occupied by agriculture, with significant areas of natural vegetation" was not chosen despite a relatively large coverage of vegetation plots because it mixes natural and anthropogenic land use. Agriculture is of interest because, as mentioned above, it is the major land use type driving terrestrial and freshwater biodiversity loss. ${ }^{1}$ Forest is also a suitable choice because the potential natural vegetation of Germany would mostly be (broad-leaved and mixed) forest. ${ }^{31}$

Since not all forests are natural, they were further classified using global data from Schulze et al. at a $1 \mathrm{~km}$ resolution. ${ }^{32}$ They distinguish four forest classes: primary, naturally regrown, planted, and unclassified. Planted forests were excluded from further analysis. After the selection of land use classes, 2197 vegetation plots remained for further analysis.

Natural Experiment. Natural experiments are observational studies designed as quasi experiments which, similar to controlled experiments, compare treatment and control groups. ${ }^{33}$ In this study, the treatment groups are the vegetation plots with agricultural (anthropogenic) land uses, and the control groups are the plots with forest (natural) land uses.

Besides land use, environmental covariates, such as climate conditions and soil properties, can influence functional diversity. They could confound the analysis of the effects of land use on functional diversity, and therefore need to be accounted for. WorldClim 2 provides global climate data at a 1 $\mathrm{km}$ resolution. ${ }^{34}$ Climate variables initially considered include annual mean temperature, temperature seasonality, maximum temperature of warmest month, minimum temperature of coldest month, annual precipitation, precipitation of wettest month, precipitation of driest month, and precipitation seasonality. The European Soil Data Centre (ESDAC) provides European soil data at a $500 \mathrm{~m}$ resolution. ${ }^{35,36}$ Soil variables initially considered include organic carbon, $\mathrm{pH}$, clay content, sand content, silt content, bulk density, and available water capacity.

Correlation coefficients served to select a subset of environmental covariates by aiming at correlations with the response variable (functional diversity) but not among covariates. $^{21} \mathrm{We}$ selected a Spearman correlation threshold of maximally 0.5 for the trait selection to avoid high correlations among covariates and minimally 0.1 with functional diversity to avoid negligible correlations with the response variable, $^{22}$ ideally for the average correlation with the three functional diversity indices and at least with one of them. These criteria resulted in the selection of the environmental covariates annual precipitation, minimum temperature, and sand content. The absolute correlation coefficients between environmental covariates ranged from 0.117 to 0.359 (SI Table S3). Although there is no a priori relationship between species richness and functional richness, functional richness may decrease with lower species coverage. ${ }^{14}$ Therefore, the ratio of the number of species with known trait values to the total number of species at a plot was also considered as a covariate.

Propensity score matching enables to match sample pairs of control and treatment groups by balancing covariates. ${ }^{37}$ As such, it allows to design an observational study as a natural experiment and to reduce selection bias by accounting for confounding covariates. ${ }^{38,39}$ Propensity scores estimate the probability of treatment given a set of covariates. Propensity scores are estimated by logistic regression, as implemented in the $\mathrm{R}$ package MatchIt ${ }^{40}$ version 3.0.2. Both control and treatment samples were discarded if they fell outside the common support. That happens if the propensity score for a certain set of covariates is 0 or 1 , leaving no chance for both control and treatment to occur with this set. ${ }^{37}$ Samples from the control (forest) and treatment (agriculture) group were matched if their propensity scores were similar, using nearest neighbor matching, which has a similar performance to optimal matching ${ }^{41}$ but is less computationally intensive. ${ }^{42}$ The caliper (the maximum allowed difference between matched samples) and the order of matching influence the matching quality. The most suitable caliper differs by case and faces a trade-off between precision and number of matches. To be consistent among the land use pairs, we followed the general recommendation of using a caliper of 0.25 standard deviations of the propensity score. ${ }^{42,43}$ Samples were matched without replacement in descending order starting with the highest propensity score, as it is most challenging to find a match for this sample. ${ }^{42}$ Matching was done separately for all nine combinations of control and treatment land uses.

The balance of covariates between control and treatment groups indicates the quality of the matching. ${ }^{37}$ Several procedures exist to assess the balance, and we used the absolute standardized bias. The standardized bias is defined as the difference in sample averages between treatment and control groups as a percentage of the square root of the average of sample variances in both groups. ${ }^{37}$ This bias, that is, the imbalance, should reduce after matching. Generally, a bias below $25 \%$ is desired. ${ }^{43}$

After matching sample pairs, the difference in functional diversity between control and treatment groups was investigated. We calculated the medians and interquartile ranges of both and tested the significance of the shift in the location of the distributions with the Wilcoxon signed-rank test. ${ }^{44}$ While having less statistical power, a nonparametric test does not rely on the assumption of normality. Since the data in this study were far from normally distributed, and we judged the sample sizes after matching as not sufficiently large for the central limit theorem to apply, we considered a nonparametric test as more appropriate.

Characterization Factors. Characterization factors (CFs) were derived based on the median functional diversities of matched sample pairs for each of nine land use combinations. The characterization factor for local land occupation impacts equals the difference in ecosystem quality $(\Delta Q)$ between the occupied land use (subscript occ) and a reference state (subscript ref), such as here the natural land use. ${ }^{45}$ In this 


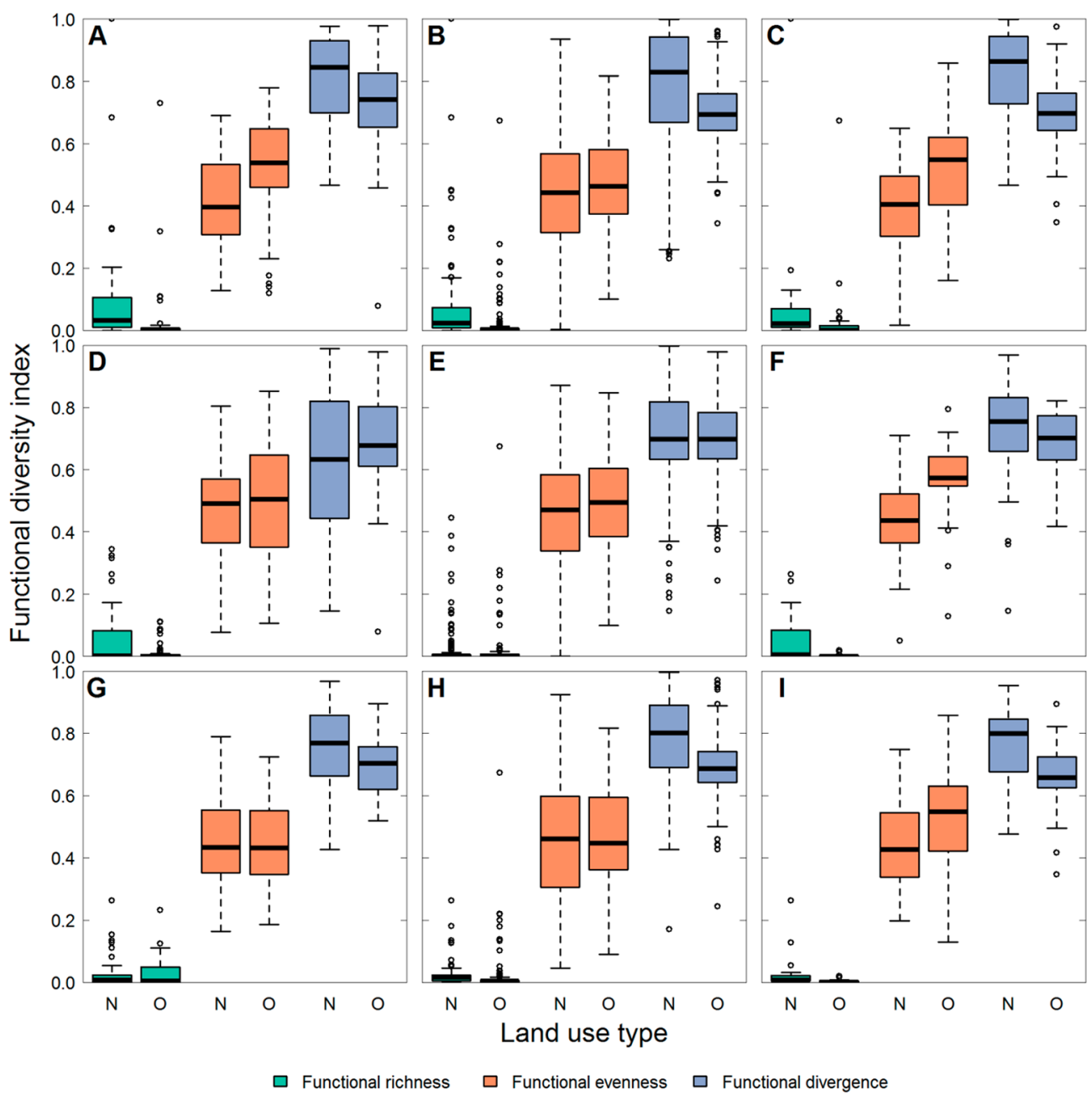

Figure 2. Functional plant diversity of natural (N) and occupied (O) land use. (A) Broad-leaved forest vs nonirrigated arable land, (B) broadleaved forest vs pasture, (C) broad-leaved forest vs complex cultivation pattern, (D) coniferous forest vs nonirrigated arable land, (E) coniferous forest vs pasture, $(\mathrm{F})$ coniferous forest vs complex cultivation pattern, $(\mathrm{G})$ mixed forest vs nonirrigated arable land, $(\mathrm{H})$ mixed forest vs pasture, $(\mathrm{I})$ mixed forest vs complex cultivation pattern. See Table 1 for results from the statistical analysis of the patterns.

study, ecosystem quality is measured as relative functional diversity (FD), resulting in the following equation:

$$
\mathrm{CF}=\Delta Q=1-\frac{\mathrm{FD}_{\mathrm{occ}}}{\mathrm{FD}_{\mathrm{ref}}}
$$

We propose the CF to be expressed in the potentially disappeared fraction of functional diversity $\left(\mathrm{PDF}_{\mathrm{FD}}\right)$, similar to the commonly used unit of potentially disappeared fraction of species (PDF). The three functional diversity components result in three CFs, representing functional richness, evenness, and divergence, for each land use combination.

\section{RESULTS}

Differences in Functional Plant Diversity. All nine land use combinations follow similar trends in functional plant diversity: a decrease in functional richness, an increase in functional evenness, and a decrease in functional divergence for anthropogenic relative to natural land use (Figure 2). For broad-leaved forest, the differences with all three agricultural land use types are in line with this general trend and statistically significant for all three functional diversity indices (Table 1). Coniferous forest deviates from this trend with a slight, significant increase in divergence when compared to nonirrigated arable land and a nonsignificant increase in richness when compared to pastures. Mixed forests show a slight decrease in evenness compared to two out of three agricultural land uses, but both are not statistically significant. The other differences follow the general trend.

The balance of covariates generally improved after propensity score matching (SI Table S4). Not all covariates for all land use combinations reached the desired maximum standardized bias of $25 \%$. Still, the bias strongly reduced, on average, across the four covariates for all nine land use combinations. For each land use combination, several vegetation plots either had to be discarded or could not be matched (SI Figure S2). The remaining sample size ranged from 26 to 193 (SI Table S5).

Characterization Factors. Consistent with the trends observed above, most characterization factors for functional richness and divergence are positive and indicate a loss, and most characterization factors for functional evenness are negative and indicate a gain in the respective functional diversity components upon land use occupation (Table 2). The only gain in functional richness resulted from the comparison of coniferous forest to pasture and was very low and statistically insignificant. Significant losses ranged from 0.56 to $0.95 \mathrm{PDF}_{\mathrm{FD}}$. The significant gains in functional 
Table 1. Statistics of Functional Plant Diversity after Propensity Score Matching ${ }^{a}$

\begin{tabular}{|c|c|c|c|c|c|c|}
\hline \multirow[b]{2}{*}{ land use } & \multicolumn{2}{|c|}{ FRic } & \multicolumn{2}{|c|}{ FEve } & \multicolumn{2}{|c|}{ FDiv } \\
\hline & median & IQR & median & IQR & median & IQR \\
\hline FBL & 0.0322 & 0.0928 & 0.3967 & 0.2250 & 0.8454 & 0.2261 \\
\hline ANI & 0.0025 & 0.0068 & 0.5391 & 0.1846 & 0.7415 & 0.1684 \\
\hline$p$-value & \multicolumn{2}{|c|}{$1.02 \times 10^{-07 * *}$} & \multicolumn{2}{|c|}{$1.63 \times 10^{-5 * *}$} & \multicolumn{2}{|c|}{$0.00137 * *$} \\
\hline FBL & 0.0233 & 0.0646 & 0.4427 & 0.2533 & 0.8298 & 0.2745 \\
\hline APS & 0.0040 & 0.0058 & 0.4628 & 0.2081 & 0.6947 & 0.1189 \\
\hline$p$-value & \multicolumn{2}{|c|}{$5.19 \times 10^{-12 * *}$} & \multicolumn{2}{|c|}{$0.0508 \bullet$} & \multicolumn{2}{|c|}{$8.17 \times 10^{-5 * *}$} \\
\hline FBL & 0.0217 & 0.0599 & 0.4044 & 0.1938 & 0.8643 & 0.2162 \\
\hline $\mathrm{ACP}$ & 0.0012 & 0.0141 & 0.5493 & 0.2184 & 0.6983 & 0.1199 \\
\hline$p$-value & \multicolumn{2}{|c|}{$4.52 \times 10^{-6 * *}$} & \multicolumn{2}{|c|}{$0.000921^{* *}$} & \multicolumn{2}{|c|}{$0.000179 * *$} \\
\hline $\mathrm{FCO}$ & 0.0022 & 0.0822 & 0.4917 & 0.2025 & 0.6329 & 0.3654 \\
\hline ANI & 0.0010 & 0.0048 & 0.5042 & 0.2933 & 0.6781 & 0.1896 \\
\hline$p$-value & \multicolumn{2}{|c|}{$0.00969 * *$} & \multicolumn{2}{|c|}{0.303} & \multicolumn{2}{|c|}{$0.0266^{*}$} \\
\hline $\mathrm{FCO}$ & 0.0023 & 0.0058 & 0.4706 & 0.2444 & 0.6983 & 0.1856 \\
\hline APS & 0.0025 & 0.0063 & 0.4942 & 0.2183 & 0.6975 & 0.1488 \\
\hline p-value & \multicolumn{2}{|c|}{0.662} & \multicolumn{2}{|c|}{0.199} & \multicolumn{2}{|c|}{0.212} \\
\hline $\mathrm{FCO}$ & 0.0063 & 0.0820 & 0.4363 & 0.1473 & 0.7551 & 0.1664 \\
\hline $\mathrm{ACP}$ & 0.0007 & 0.0015 & 0.5740 & 0.0876 & 0.7017 & 0.1372 \\
\hline p-value & \multicolumn{2}{|c|}{$0.000217^{* *}$} & \multicolumn{2}{|c|}{$0.0254 *$} & \multicolumn{2}{|c|}{0.423} \\
\hline FMX & 0.0081 & 0.0224 & 0.4332 & 0.1932 & 0.7694 & 0.1921 \\
\hline ANI & 0.0044 & 0.0455 & 0.4314 & 0.2022 & 0.7050 & 0.1322 \\
\hline$p$-value & \multicolumn{2}{|c|}{0.388} & \multicolumn{2}{|c|}{0.920} & \multicolumn{2}{|c|}{$0.0588 \bullet$} \\
\hline FMX & 0.0161 & 0.0177 & 0.4620 & 0.2822 & 0.8011 & 0.1995 \\
\hline APS & 0.0038 & 0.0062 & 0.4476 & 0.2307 & 0.6867 & 0.0988 \\
\hline$p$-value & \multicolumn{2}{|c|}{$4.76 \times 10^{-7 * *}$} & \multicolumn{2}{|c|}{0.294} & \multicolumn{2}{|c|}{$1.75 \times 10^{-7 * *}$} \\
\hline FMX & 0.0081 & 0.0162 & 0.4264 & 0.1942 & 0.7995 & 0.1631 \\
\hline $\mathrm{ACP}$ & 0.0008 & 0.0042 & 0.5488 & 0.2006 & 0.6474 & 0.0951 \\
\hline$p$-value & \multicolumn{2}{|c|}{$7.96 \times 10^{-6 * *}$} & \multicolumn{2}{|c|}{$0.0264^{*}$} & \multicolumn{2}{|c|}{$0.0103 *$} \\
\hline
\end{tabular}

${ }^{a}$ Functional diversity was measured by three indices: functional richness (FRic), functional evenness (FEve), and functional divergence (FDiv). The forest types include broad-leaved forest (FBL), coniferous forest (FCO), and mixed forest (FMX). The agricultural land use types include non-irrigated arable land (ANI), pastures (APS), and complex cultivation patterns (ACP). The statistics are the nonparametric median and interquartile range (IQR). $P$-values refer to the Wilcoxon signed-rank test: no symbol = nonsignificant, $\bullet=p$-value $\leq 0.1, *=p$-value $\leq 0.05, * *=p$-value $\leq$ 0.01. See Figure 2 for a visualization of the differences.

evenness ranged from negative 0.045 to $0.36 \mathrm{PDF}_{\mathrm{FD}}$. The only two (out of nine) losses of functional evenness resulted from a comparison of mixed forest to nonirrigated arable land and pasture. Both were statistically insignificant. Significant losses of functional divergence ranged from 0.084 to $0.19 \mathrm{PDF}_{\mathrm{FD}}$. The only gain in functional divergence resulted from a comparison of coniferous forest to nonirrigated arable land and was statistically significant. However, the gain is low.

Overall, the functional diversity of broad-leaved forests is most affected by agricultural land use, and coniferous forests are least affected (Table 2). Complex cultivation patterns drive the most significant loss of functional diversity across the three forest types. The only land use combination where the anthropogenic land use seems not to affect functional diversity is for the comparison of coniferous forest and pasture.

\section{DISCUSSION}

A Natural Experiment to Derive Characterization Factors for LCAs. Natural or quasi experiments, as carried out here, offer great potential for investigating cause-effect
Table 2. Characterization Factors (CFs) for Land-Use Driven Loss of Functional Plant Diversity ${ }^{a}$

\begin{tabular}{|c|c|c|c|c|}
\hline $\begin{array}{l}\text { reference land } \\
\text { use }\end{array}$ & occupied land use & $\mathrm{CF}_{\text {FRic }}$ & $\mathrm{CF}_{\mathrm{FEve}}$ & $\mathrm{CF}_{\mathrm{FDiv}}$ \\
\hline \multirow[t]{3}{*}{$\begin{array}{l}\text { broad-leaved } \\
\text { forest }\end{array}$} & $\begin{array}{l}\text { nonirrigated arable } \\
\text { land }\end{array}$ & $0.922 * *$ & $-0.359 * *$ & $0.123^{* *}$ \\
\hline & pasture & $0.823^{* *}$ & $-0.045 \bullet$ & $0.163^{* *}$ \\
\hline & $\begin{array}{l}\text { complex cultivation } \\
\text { pattern }\end{array}$ & $0.946^{* * *}$ & $-0.358^{* *}$ & $0.192^{* *}$ \\
\hline \multirow[t]{3}{*}{$\begin{array}{l}\text { coniferous } \\
\text { forest }\end{array}$} & $\begin{array}{l}\text { nonirrigated arable } \\
\text { land }\end{array}$ & $0.560^{* * *}$ & -0.025 & $-0.072 *$ \\
\hline & pasture & -0.090 & -0.050 & 0.001 \\
\hline & $\begin{array}{l}\text { complex cultivation } \\
\text { pattern }\end{array}$ & $0.884^{* *}$ & $-0.316^{*}$ & 0.071 \\
\hline \multirow[t]{3}{*}{ mixed forest } & $\begin{array}{l}\text { nonirrigated arable } \\
\text { land }\end{array}$ & 0.458 & 0.004 & $0.084 \bullet$ \\
\hline & pasture & $0.766^{* *}$ & 0.031 & $0.143^{* *}$ \\
\hline & $\begin{array}{l}\text { complex cultivation } \\
\text { pattern }\end{array}$ & $0.907 * *$ & $-0.287^{*}$ & $0.178^{*}$ \\
\hline
\end{tabular}

${ }^{a} \mathrm{CFs}$ are expressed in potentially disappeared fraction of functional diversity $\left(\mathrm{PDF}_{\mathrm{FD}}\right)$ and cover three functional diversity components: functional richness (FRic), evenness (FEve), and divergence (FDiv). Significance relates to the Wilcoxon signed-rank test (Table 1). No symbol $=$ nonsignificant, $\bullet=p$-value $\leq 0.1, *=p$-value $\leq 0.05, * *=$ $p$-value $\leq 0.01$.

relationships in ecological and sustainability research. ${ }^{38,39}$ They are especially valuable where controlled experiments are impractical or unethical and where nonexperimental observational studies are inadequate to infer causality. ${ }^{33}$ Propensity score matching has proven useful in this study to design the natural experiment, as the balance of confounding covariates strongly improved. The technique involves several decisions, such as the model to estimate the propensity scores, the matching algorithm, and the selection of covariates, which can all influence the results. ${ }^{37}$ As such, it requires careful choices and transparent documentation. Besides propensity score matching, alternative matching approaches, regression discontinuity designs, difference-in-differences models, and instrumental variables could serve the same purpose of designing natural experiments. ${ }^{38}$ Using a natural experiment, this study provided a proof of concept for developing characterization factors, and demonstrated the framework based on data from Germany. Given data availability, the same approach can be applied to other regions and larger scales. TRY provides plant traits at the global level, ${ }^{16}$ and the European Vegetation Archive (EVA) ${ }^{46}$ and sPlot $^{15}$ are European and global vegetation plot databases.

An important result of the study is the high consistency of functional diversity impacts across different land use types. Consistently, functional richness and divergence decreased, while functional evenness showed an opposite trend (Figure 2, Table 2). Moreover, functional evenness negatively correlates with functional richness and divergence (SI Table S3). This pattern is consistent with other studies (e.g., ref 26) and points to a fundamental feature of functional diversity: With a decrease in environmental quality, the abundance of species becomes increasingly skewed and, while rare species might get lost (decreasing functional richness), common species become less dominant (increasing functional evenness). Hence, it seems that, at a local scale, evenness may change in different directions than at a large scale, where evenness is rather 
declining and negatively affects the resilience of the ecosystem as a whole. ${ }^{26}$

The characterization factors also clearly show that functional richness is most strongly negatively affected by land use. This feature has-to our knowledge- not yet been described in ecological literature. It suggests, however, that the total trait space for alternative species strategies is much more strongly affected than the distribution of multiple strategies within that space. In turn, this suggests that the direct impacts of the decline in habitat quality are dominant in the biodiversity effects of land use. Such impacts may be generalized across land use types by using land use intensity, which is known to relate to biodiversity changes. ${ }^{47}$ Land use intensity has so far been considered in LCA only in a few characterization models. ${ }^{8,11}$

While, in general, characterization factors were highly consistent, they can differ among land use types. The forest type and the agricultural land use type matter. For example, agricultural land use affects the functional diversity of originally broad-leaved forests more than of coniferous forests. Such insights are important to refining and improving impact assessments of LCAs. It demonstrates that impact assessment of land use can benefit from a higher detail of land use classes.

Choice of Functional Diversity Metrics for LCAs. This study provides the first comprehensive quantification, based on coupling several large biodiversity-related databases, of land use impacts on functional diversity. Functional diversity adds immense value to biodiversity impact assessment, as it links more closely to ecosystem functioning than species richness, which makes its importance more obvious. Based on the framework provided in this study, we hope to encourage other studies to include functional diversity metrics.

While being more closely linked to ecosystem functioning, functional diversity also entails a higher complexity and is hence more difficult to compute and requires more data. First of all, functional diversity consists of multiple componentsfunctional richness, evenness, and divergence-for which different metrics have been developed. Here, we followed the recommendation by Ahmed et al. ${ }^{13}$ and used the indicator set developed by Villéger et al. ${ }^{28}$ Other metrics might lead to slightly deviating results.

Second is the selection of the traits, which in turn depends on the choice of taxa. Here, we deliberately chose plants as the only taxon. Plants are at the base of the food web, having strong bottom-up effects on multiple higher trophic levels. ${ }^{48}$ Plant diversity correlates with the diversity of other taxa even after accounting for the influence of abiotic factors, ${ }^{49}$ and positively affects ecosystem functions. ${ }^{50}$ Inclusion of multiple taxa, although that would allow covering a wider range of ecosystem functioning, ${ }^{51}$ would also imply multiple independent biodiversity impact estimates, as it is not straightforward to compare traits (or species numbers) across taxa. Therefore, we opted for one, but representative, taxon. The selected traits should link to the ecosystem functioning or property of interest. ${ }^{9}$ In this study, we opted for selecting (uncorrelated) traits that are known to relate to general ecosystem functioning aspects. It is facilitated by our selection from different organs: leaves (specific leaf area), stem (canopy height), and seeds (seed number and mass). Our trait set, while derived differently, is highly similar to trait sets that allow differentiating among vegetation types. ${ }^{52}$ When deriving functional diversity for other taxa, trait selection might be more complicated, as the diversity in strategies and hence traits is larger and less understood. ${ }^{53}$

Third is the choice of the number of traits. Particularly functional richness seems to be very sensitive to the number of traits included, while functional evenness and functional divergence (as calculated here) are only slightly influenced. ${ }^{54}$ Four traits can already be sufficient to characterize the functional diversity of plants if correlation among traits is avoided and traits cover at least three different organs, ${ }^{55}$ as done here. Still, data availability, for instance, due to the lower availability of root traits vs leaf traits, ${ }^{56}$ may lead to suboptimal characterizations of functional diversity. Data availability issues may also cause traits to be more correlated and hence linked to few ecosystem functions. It is partially resolved by using PCoAs for calculating functional diversity, which also reduces computation times. ${ }^{57}$ The drawback of using PCoAs is that the transformation may not maintain actual differences in trait expressions among species. ${ }^{58}$

Finally, both the number and the identity of the selected traits depend on the quality of the database. The quality of the trait database does not only refer to the number of observations but also to the availability of geolocations, adequate species identifications, and quality control of the trait values. With available geolocations, trait variations within species may potentially also be accounted for. Some traits vary more within than among species, and location-specific trait estimates may improve functional diversity estimates. ${ }^{53}$

Implementation of Functional Diversity Metrics in LCAs. The derived characterization factors for the marginal land occupation of former forests with agricultural land can readily be integrated and applied in LCAs. We are aware that examining three functional diversity metrics simultaneously may decrease the equivocality of the impact assessments. Usually, more aggregated results, such as endpoints compared to midpoints, offer less transparency but are easier to communicate to decision-makers. ${ }^{59}$ Aggregation is already challenging for different taxa, and has only been done statistically and without ecological reasoning. ${ }^{60}$ Aggregating different functional diversity components would be equally challenging. One possibility to determine objective weights for aggregation in multicriteria decision analyses is the least-square method, in which the root-mean-square deviation (RMSD) is calculated for each criterion. ${ }^{61}$ These can be translated to weights by dividing by the sum of RMSDs. In our case, this would result in weights of 0.57 for functional richness, 0.28 for functional evenness, and 0.15 for functional divergence. However, aggregation with predetermined weights does not do justice to the multifaceted impacts on biodiversity. Therefore, we strongly advocate the use of all three metrics, which can be combined with a multicriteria decision analysis or multiattribute analysis for evaluation in LCAs. ${ }^{62}$

With the strongly increased availability of public data on a multitude of environmental conditions and biodiversity features, $^{63}$ a data-driven approach-as exemplified in this study-is increasingly feasible for impact assessments. While focusing on land use impacts, similar analyses may be done for toxicity (with available information on pesticides in surface waters), water scarcity (hydrology data sets), and others. Likewise, we consider the derived characterization factors to be likely representative of temperate regions with intensive land use (as occurring in Western Europe and parts of the United States). Our framework is, however, equally well suited for deriving characterization factors for other regions. With the 
necessary data becoming increasingly available, this study's flexible framework paves the way for integrating functional diversity into standard LCIA.

\section{ASSOCIATED CONTENT}

\section{(s) Supporting Information}

The Supporting Information is available free of charge at https://pubs.acs.org/doi/10.1021/acs.est.9b07228.

Supporting figures and tables related to the study area, correlations, and propensity score matching (PDF)

\section{AUTHOR INFORMATION}

\section{Corresponding Author}

Laura Scherer - Institute of Environmental Sciences (CML), Leiden University, 2333 CC Leiden, The Netherlands; ○ orcid.org/0000-0002-0194-9942; Email: 1.a.scherer@ cml.leidenuniv.nl

\section{Authors}

Sven A. van Baren - Institute of Environmental Sciences (CML), Leiden University, 2333 CC Leiden, The Netherlands

Peter M. van Bodegom - Institute of Environmental Sciences (CML), Leiden University, 2333 CC Leiden, The Netherlands

Complete contact information is available at:

https://pubs.acs.org/10.1021/acs.est.9b07228

\section{Author Contributions}

L.S. conceived the idea; L.S. and P.v.B. designed the study; S.v.B. collected the data and performed the analysis; L.S. wrote the manuscript with input from all authors.

\section{Notes}

The authors declare no competing financial interest.

\section{ABBREVIATIONS}

\section{CF characterization factor}

FDiv functional divergence

FEve functional evenness

FRic functional richness

LCA life cycle assessment

LCIA life cycle impact assessment

PCoA principal coordinate analysis

\section{REFERENCES}

(1) IPBES. Global Assessment on Biodiversity and Ecosystem Services, 2019.

(2) Tittensor, D. P.; Walpole, M.; Hill, S. L. L.; Boyce, D. G.; Britten, G. L.; Burgess, N. D.; Butchart, S. H. M.; Leadley, P. W.; Regan, E. C.; Alkemade, R.; Baumung, R.; Bellard, C.; Bouwman, L.; Bowles-Newark, N. J.; Chenery, A. M.; Cheung, W. W. L.; Christensen, V.; Cooper, H. D.; Crowther, A. R.; Dixon, M. J. R.; Galli, A.; Gaveau, V.; Gregory, R. D.; Gutierrez, N. L.; Hirsch, T. L.; Höft, R.; Januchowski-Hartley, S. R.; Karmann, M.; Krug, C. B.; Leverington, F. J.; Loh, J.; Lojenga, R. K.; Malsch, K.; Marques, A.; Morgan, D. H. W.; Mumby, P. J.; Newbold, T.; Noonan-Mooney, K.; Pagad, S. N.; Parks, B. C.; Pereira, H. M.; Robertson, T.; Rondinini, C.; Santini, L.; Scharlemann, J. P. W.; Schindler, S.; Sumaila, U. R.; Teh, L. S. L.; Kolck Van, J.; Visconti, P.; Ye, Y. A mid-term analysis of progress toward international biodiversity targets. Science 2014, 346, 241.

(3) Newbold, T.; Hudson, L. N.; Arnell, A. P.; Contu, S.; Palma de, A.; Ferrier, S.; Hill, S. L. L.; Hoskins, A. J.; Lysenko, I.; Phillips, H. R. P.; Burton, V. J.; Chng, C. W. T.; Emerson, S.; Di, Gao; Pask-Hale, G.; Hutton, J.; Jung, M.; Sanchez-Ortiz, K.; Simmons, B. I.; Whitmee, S.; Zhang, H.; Scharlemann, J. P. W.; Purvis, A. Has land use pushed terrestrial biodiversity beyond the planetary boundary? A global assessment. Science 2016, 353, 288.

(4) Hellweg, S.; Milà i Canals, L. Emerging approaches, challenges and opportunities in life cycle assessment. Science 2014, 344, 1109.

(5) Curran, M.; de Souza, D. M.; Anton, A.; Teixeira, R. F. M.; Michelsen, O.; Vidal-Legaz, B.; Sala, S.; Milà i Canals, L. How Well Does LCA Model Land Use Impacts on Biodiversity? A Comparison with Approaches from Ecology and Conservation. Environ. Sci. Technol. 2016, 50, 2782-2795.

(6) Taelman, S. E.; Schaubroeck, T.; de Meester, S.; Boone, L.; Dewulf, J. Accounting for land use in life cycle assessment: The value of NPP as a proxy indicator to assess land use impacts on ecosystems. Sci. Total Environ. 2016, 550, 143-156.

(7) Fehrenbach, H.; Grahl, B.; Giegrich, J.; Busch, M. Hemeroby as an impact category indicator for the integration of land use into life cycle (impact) assessment. Int. J. Life Cycle Assess. 2015, 20, 15111527.

(8) Chaudhary, A.; Brooks, T. M. Land use intensity-specific global characterization factors to assess product biodiversity footprints. Environ. Sci. Technol. 2018, 52, 5094-5104.

(9) Cadotte, M. W.; Carscadden, K.; Mirotchnick, N. Beyond species: Functional diversity and the maintenance of ecological processes and services. J. Appl. Ecol. 2011, 48, 1079-1087.

(10) Woods, J. S.; Damiani, M.; Fantke, P.; Henderson, A. D.; Johnston, J. M.; Bare, J.; Sala, S.; de Souza, D. M.; Pfister, S.; Posthuma, L.; Rosenbaum, R. K.; Verones, F. Ecosystem quality in LCIA: Status quo, harmonization, and suggestions for the way forward. Int. J. Life Cycle Assess. 2018, 23, 1995-2006.

(11) de Souza, D. M.; Flynn, D. F. B.; DeClerck, F.; Rosenbaum, R. K.; de Melo Lisboa, H.; Koellner, T. Land use impacts on biodiversity in LCA: Proposal of characterization factors based on functional diversity. Int. J. Life Cycle Assess. 2013, 18, 1231-1242.

(12) Petchey, O. L.; Gaston, K. J. Functional diversity (FD), species richness and community composition. Ecology Letters 2002, 5, 402411.

(13) Ahmed, D. A.; van Bodegom, P. M.; Tukker, A. Evaluation and selection of functional diversity metrics with recommendations for their use in life cycle assessments. Int. J. Life Cycle Assess. 2019, 24, $485-500$.

(14) Mason, N. W. H.; Mouillot, D.; Lee, W. G.; Wilson, J. B. Functional richness, functional evenness and functional divergence: The primary components of functional diversity. Oikos 2005, 111, $112-118$.

(15) Bruelheide, H.; Dengler, J.; Jiménez-Alfaro, B.; Purschke, O.; Hennekens, S. M.; Chytrý, M.; Pillar, V. D.; Jansen, F.; Kattge, J.; Sandel, B.; Aubin, I.; Biurrun, I.; Field, R.; Haider, S.; Jandt, U.; Lenoir, J.; Peet, R. K.; Peyre, G.; Sabatini, F. M.; Schmidt, M.; Schrodt, F.; Winter, M.; Aćíc, S.; Agrillo, E.; Alvarez, M.; Ambarlı, D.; Angelini, P.; Apostolova, I.; Arfin Khan, M. A. S.; Arnst, E.; Attorre, F.; Baraloto, C.; Beckmann, M.; Berg, C.; Bergeron, Y.; Bergmeier, E.; Bjorkman, A. D.; Bondareva, V.; Borchardt, P.; Botta-Dukát, Z.; Boyle, B.; Breen, A.; Brisse, H.; Byun, C.; Cabido, M. R.; Casella, L.; Cayuela, L.; Ćerný, T.; Chepinoga, V.; Csiky, J.; Curran, M.; Ćušterevska, R.; Dajić Stevanović, Z.; de Bie, E.; de Ruffray, P.; de Sanctis, M.; Dimopoulos, P.; Dressler, S.; Ejrnæs, R.; El-Sheikh, M. A. E.-R. M.; Enquist, B.; Ewald, J.; Fagúndez, J.; Finckh, M.; Font, X.; Forey, E.; Fotiadis, G.; García-Mijangos, I.; de Gasper, A. L.; Golub, V.; Gutierrez, A. G.; Hatim, M. Z.; He, T.; Higuchi, P.; Holubová, D.; Hölzel, N.; Homeier, J.; Indreica, A.; Işık Gürsoy, D.; Jansen, S.; Janssen, J.; Jedrzejek, B.; Jiroušek, M.; Jürgens, N.; Kạcki, Z.; Kavgacı, A.; Kearsley, E.; Kessler, M.; Knollová, I.; Kolomiychuk, V.; Korolyuk, A.; Kozhevnikova, M.; Kozub, Ł.; Krstonošić, D.; Kühl, H.; Kühn, I.; Kuzemko, A.; Küzmič, F.; Landucci, F.; Lee, M. T.; Levesley, A.; Li, C.-F.; Liu, H.; Lopez-Gonzalez, G.; Lysenko, T.; Macanović, A.; Mahdavi, P.; Manning, P.; Marcenò, C.; Martynenko, V.; Mencuccini, M.; Minden, V.; Moeslund, J. E.; Moretti, M.; Müller, J. V.; Munzinger, J.; Niinemets, Ü.; Nobis, M.; Noroozi, J.; Nowak, A.; Onyshchenko, V.; Overbeck, G. E.; Ozinga, W. A.; Pauchard, A.; Pedashenko, H.; Peñuelas, J.; Pérez-Haase, A.; Peterka, T.; Petř́k, P.; 
Phillips, O. L.; Prokhorov, V.; Rašomavičius, V.; Revermann, R.; Rodwell, J.; Ruprecht, E.; Rūsiņa, S.; Samimi, C.; Schaminée, J. H.J.; Schmiedel, U.; Šibík, J.; Šilc, U.; Škvorc, Ž.; Smyth, A.; Sop, T.; Sopotlieva, D.; Sparrow, B.; Stančić, Z.; Svenning, J.-C.; Swacha, G.; Tang, Z.; Tsiripidis, I.; Turtureanu, P. D.; Uğurlu, E.; Uogintas, D.; Valachovič, M.; Vanselow, K. A.; Vashenyak, Y.; Vassilev, K.; VélezMartin, E.; Venanzoni, R.; Vibrans, A. C.; Violle, C.; Virtanen, R.; von Wehrden, H.; Wagner, V.; Walker, D. A.; Wana, D.; Weiher, E.; Wesche, K.; Whitfeld, T.; Willner, W.; Wiser, S.; Wohlgemuth, T.; Yamalov, S.; Zizka, G.; Zverev, A. sPlot - A new tool for global vegetation analyses. J. Veg Sci. 2019, 30, 161-186.

(16) Kattge, J.; Díaz, S.; Lavorel, S.; Prentice, I. C.; Leadley, P.; Bönisch, G.; Garnier, E.; Westoby, M.; Reich, P. B.; Wright, I. J.; Cornelissen, J. H. C.; Violle, C.; Harrison, S. P.; van Bodegom, P. M.; Reichstein, M.; Enquist, B. J.; Soudzilovskaia, N. A.; Ackerly, D. D.; Anand, M.; Atkin, O.; Bahn, M.; Baker, T. R.; Baldocchi, D.; Bekker, R.; Blanco, C. C.; Blonder, B.; Bond, W. J.; Bradstock, R.; Bunker, D. E.; Casanoves, F.; Cavender-Bares, J.; Chambers, J. Q.; Chapin III, F. S.; Chave, J.; Coomes, D.; Cornwell, W. K.; Craine, J. M.; Dobrin, B. H.; Duarte, L.; Durka, W.; Elser, J.; Esser, G.; Estiarte, M.; Fagan, W. F.; Fang, J.; Fernández-Méndez, F.; Fidelis, A.; Finegan, B.; Flores, O.; Ford, H.; Frank, D.; Freschet, G. T.; Fyllas, N. M.; Gallagher, R. V.; Green, W. A.; Gutierrez, A. G.; Hickler, T.; Higgins, S. I.; Hodgson, J. G.; Jalili, A.; Jansen, S.; Joly, C. A.; Kerkhoff, A. J.; Kirkup, D.; Kitajima, K.; Kleyer, M.; Klotz, S.; Knops, J. M. H.; Kramer, K.; Kühn, I.; Kurokawa, H.; Laughlin, D.; Lee, T. D.; Leishman, M.; Lens, F.; Lenz, T.; Lewis, S. L.; Lloyd, J.; Llusiá, J.; Louault, F.; Ma, S.; Mahecha, M. D.; Manning, P.; Massad, T.; Medlyn, B. E.; Messier, J.; Moles, A. T.; Müller, S. C.; Nadrowski, K.; Naeem, S.; Niinemets, Ü.; Nöllert, S.; Nüske, A.; Ogaya, R.; Oleksyn, J.; Onipchenko, V. G.; Onoda, Y.; Ordoñez, J.; Overbeck, G.; Ozinga, W. A.; Patiño, S.; Paula, S.; Pausas, J. G.; Peñuelas, J.; Phillips, O. L.; Pillar, V. D.; Poorter, H.; Poorter, L.; Poschlod, P.; Prinzing, A.; Proulx, R.; Rammig, A.; Reinsch, S.; Reu, B.; Sack, L.; Salgado-Negret, B.; Sardans, J.; Shiodera, S.; Shipley, B.; Siefert, A.; Sosinski, E.; Soussana, J.-F.; Swaine, E.; Swenson, N.; Thompson, K.; Thornton, P.; Waldram, M.; Weiher, E.; White, M.; White, S.; Wright, S. J.; Yguel, B.; Zaehle, S.; Zanne, A. E.; Wirth, C. TRY - a global database of plant traits. Global Change Biology 2011, 17, 2905-2935.

(17) van Bodegom, P. M.; Douma, J. C.; Verheijen, L. M. A fully traits-based approach to modeling global vegetation distribution. Proc. Natl. Acad. Sci. U. S. A. 2014, 111, 13733.

(18) Kleyer, M.; Bekker, R. M.; Knevel, I. C.; Bakker, J. P.; Thompson, K.; Sonnenschein, M.; Poschlod, P.; van Groenendael, J. M.; Klimeš, L.; Klimešová, J.; Klotz, S.; Rusch, G. M.; Hermy, M.; Adriaens, D.; Boedeltje, G.; Bossuyt, B.; Dannemann, A.; Endels, P.; Götzenberger, L.; Hodgson, J. G.; Jackel, A.-K.; Kühn, I.; Kunzmann, D.; Ozinga, W. A.; Römermann, C.; Stadler, M.; Schlegelmilch, J.; Steendam, H. J.; Tackenberg, O.; Wilmann, B.; Cornelissen, J. H. C.; Eriksson, O.; Garnier, E.; Peco, B. The LEDA Traitbase: A database of life-history traits of the Northwest European flora. J. Ecol. 2008, 96, $1266-1274$.

(19) Kleyer, M.; Bekker, R. M.; Knevel, I. C.; Bakker, J. P.; Thompson, K.; Sonnenschein, M.; Poschlod, P.; Groenendael van, J. M.; Klimeš, L.; Klimešová, J.; Klotz, S.; Rusch, G. M.; Hermy, M.; Adriaens, D.; Boedeltje, G.; Bossuyt, B.; Dannemann, A.; Endels, P.; Götzenberger, L.; Hodgson, J. G.; Jackel, A.-K.; Kühn, I.; Kunzmann, D.; Ozinga, W. A.; Römermann, C.; Stadler, M.; Schlegelmilch, J.; Steendam, H. J.; Tackenberg, O.; Wilmann, B.; Cornelissen, J. H. C.; Eriksson, O.; Garnier, E.; Peco, B. The LEDA Traitbase: A database of life-history traits of the Northwest European flora. https://uol.de/ en/landeco/research/leda (accessed 2019/4-7).

(20) Laureto, L. M. O.; Cianciaruso, M. V.; Samia, D. S. M. Functional diversity: An overview of its history and applicability. Natureza \& Conservação 2015, 13, 112-116.

(21) Murray, K.; Conner, M. M. Methods to quantify variable importance: Implications for the analysis of noisy ecological data. Ecology 2009, 90, 348-355.
(22) Scherer, L.; Curran, M.; Alvarez, M. Expanding Kenya's protected areas under the Convention on Biological Diversity to maximize coverage of plant diversity. Conservation Biology 2017, 31, $302-310$.

(23) Funk, J. L.; Larson, J. E.; Ames, G. M.; Butterfield, B. J.; Cavender-Bares, J.; Firn, J.; Laughlin, D. C.; Sutton-Grier, A. E.; Williams, L.; Wright, J. Revisiting the Holy Grail: Using plant functional traits to understand ecological processes. Biol. Rev. 2017, 92, 1156-1173.

(24) Jansen, F.; Ewald, J.; Jandt, U. VegetWeb 2.0-Neuauflage eines Vegetationsdatenportals für Deutschland. Tuexenia 2015, 35, 309319.

(25) Jansen, F. Vegetweb data basket (accessed 2019/3/7).

(26) Karadimou, E. K.; Kallimanis, A. S.; Tsiripidis, I.; Dimopoulos, P. Functional diversity exhibits a diverse relationship with area, even a decreasing one. Sci. Rep. 2016, 6, 35420EP.

(27) Cayuela, L.; La Granzow-de Cerda, I.; Albuquerque, F. S.; Golicher, D. J. taxonstand: An $\mathrm{r}$ package for species names standardisation in vegetation databases. Methods in Ecology and Evolution 2012, 3, 1078-1083.

(28) Villéger, S.; Mason, N. W. H.; Mouillot, D. New multidimensional functional diversity indices for a multifaceted framework in functional ecology. Ecology 2008, 89, 2290-2301.

(29) Laliberté, E.; Legendre, P. A distance-based framework for measuring functional diversity from multiple traits. Ecology 2010, 91, 299-305.

(30) EEA. CLC2018 Technical Guidelines; Vienna, Austria, 2017.

(31) Hengl, T.; Walsh, M. G.; Sanderman, J.; Wheeler, I.; Harrison, S. P.; Prentice, I. C. Global mapping of potential natural vegetation: An assessment of machine learning algorithms for estimating land potential. PeerJ 2018, 6, No. e5457-e5457.

(32) Schulze, K.; Malek, Ž.; Verburg, P. H. Towards better mapping of forest management patterns: A global allocation approach. For. Ecol. Manage. 2019, 432, 776-785.

(33) Messer, L. C. Natural experiment. https://www.britannica. com/science/natural-experiment.

(34) Fick, S. E.; Hijmans, R. J. WorldClim 2: New 1-km spatial resolution climate surfaces for global land areas. Int. J. Climatol 2017, 37, 4302-4315.

(35) de Brogniez, D.; Ballabio, C.; Stevens, A.; Jones, R. J. A.; Montanarella, L.; van Wesemael, B. A map of the topsoil organic carbon content of Europe generated by a generalized additive model. Eur. J. Soil Sci. 2015, 66, 121-134.

(36) Ballabio, C.; Panagos, P.; Monatanarella, L. Mapping topsoil physical properties at European scale using the LUCAS database. Geoderma 2016, 261, 110-123.

(37) Caliendo, M.; Kopeinig, S. Some practical guidance for the implementation of propensity score matching. Journal of Economic Surveys 2008, 22, 31-72.

(38) Butsic, V.; Lewis, D. J.; Radeloff, V. C.; Baumann, M.; Kuemmerle, T. Quasi-experimental methods enable stronger inferences from observational data in ecology. Basic Appl. Ecol. 2017, 19, $1-10$.

(39) Cucurachi, S.; Suh, S. Cause-effect analysis for sustainable development policy. Environ. Rev. 2017, 25, 358-379.

(40) Ho, D. E.; Imai, K.; King, G.; Stuart, E. A. MatchIt: Nonparametric preprocessing for parametric causal inference. J. Stat. Software, http://gking.harvard.edu/matchit 2011. DOI: 10.18637/ jss.v042.i08

(41) Austin, P. C. A comparison of 12 algorithms for matching on the propensity score. Statist. Med. 2014, 33, 1057-1069.

(42) Lunt, M. Selecting an Appropriate Caliper Can Be Essential for Achieving Good Balance With Propensity Score Matching. Am. J. Epidemiol. 2014, 179, 226-235.

(43) Stuart, E. A.; Rubin, D. B. Best practices in quasi-experimental designs. In Best Practices in Quantitative Methods; Osborne, J. W., Ed.; SAGE Publications, Inc.: Thousand Oaks, CA, 2008.

(44) Wilcoxon, F. Individual Comparisons by Ranking Methods. Biom. Bull. 1945, 1, 80-83. 
(45) Koellner, T.; de Baan, L.; Beck, T.; Brandão, M.; Civit, B.; Margni, M.; i Canals, L. M.; Saad, R.; de Souza, D. M.; Müller-Wenk, R. UNEP-SETAC guideline on global land use impact assessment on biodiversity and ecosystem services in LCA. Int. J. Life Cycle Assess. 2013, 18, 1188-1202.

(46) Chytrý, M.; Hennekens, S. M.; Jiménez-Alfaro, B.; Knollová, I.; Dengler, J.; Jansen, F.; Landucci, F.; Schaminée, J. H.J.; Aćić, S.; Agrillo, E.; Ambarl, D.; Angelini, P.; Apostolova, I.; Attorre, F.; Berg, C.; Bergmeier, E.; Biurrun, I.; Botta-Dukát, Z.; Brisse, H.; Campos, J. A.; Carlón, L.; Čarni, A.; Casella, L.; Csiky, J.; Cušterevska, R.; Dajić Stevanović, Z.; Danihelka, J.; de Bie, E.; de Ruffray, P.; de Sanctis, M.; Dickoré, W. B.; Dimopoulos, P.; Dubyna, D.; Dziuba, T.; Ejrnæs, R.; Ermakov, N.; Ewald, J.; Fanelli, G.; Fernández-González, F.; FitzPatrick, Ú.; Font, X.; García-Mijangos, I.; Gavilán, R. G.; Golub, V.; Guarino, R.; Haveman, R.; Indreica, A.; Işık Gürsoy, D.; Jandt, U.; Janssen, J. A.M.; Jiroušek, M.; Kącki, Z.; Kavgacı, A.; Kleikamp, M.; Kolomiychuk, V.; Krstivojević Ćuk, M.; Krstonošić, D.; Kuzemko, A.; Lenoir, J.; Lysenko, T.; Marcenò, C.; Martynenko, V.; Michalcová, D.; Moeslund, J. E.; Onyshchenko, V.; Pedashenko, H.; Pérez-Haase, A.; Peterka, T.; Prokhorov, V.; Rašomavičius, V.; Rodríguez-Rojo, M. P.; Rodwell, J. S.; Rogova, T.; Ruprecht, E.; Rūsinga, S.; Seidler, G.; Šibík, J.; Šilc, U.; Skvorc, Ž.; Sopotlieva, D.; Stančić, Z.; Svenning, J.-C.; Swacha, G.; Tsiripidis, I.; Turtureanu, P. D.; Uğurlu, E.; Uogintas, D.; Valachovič, M.; Vashenyak, Y.; Vassilev, K.; Venanzoni, R.; Virtanen, R.; Weekes, L.; Willner, W.; Wohlgemuth, T.; Yamalov, S. European Vegetation Archive (EVA): An integrated database of European vegetation plots. Appl. Veg Sci. 2016, 19, 173-180.

(47) Allan, E.; Manning, P.; Alt, F.; Binkenstein, J.; Blaser, S.; Blüthgen, N.; Böhm, S.; Grassein, F.; Hölzel, N.; Klaus, V. H.; Kleinebecker, T.; Morris, E. K.; Oelmann, Y.; Prati, D.; Renner, S. C.; Rillig, M. C.; Schaefer, M.; Schloter, M.; Schmitt, B.; Schöning, I.; Schrumpf, M.; Solly, E.; Sorkau, E.; Steckel, J.; Steffen-Dewenter, I.; Stempfhuber, B.; Tschapka, M.; Weiner, C. N.; Weisser, W. W.; Werner, M.; Westphal, C.; Wilcke, W.; Fischer, M. Land use intensification alters ecosystem multifunctionality via loss of biodiversity and changes to functional composition. Ecol Lett. 2015, $18,834-843$.

(48) Scherber, C.; Eisenhauer, N.; Weisser, W. W.; Schmid, B.; Voigt, W.; Fischer, M.; Schulze, E.-D.; Roscher, C.; Weigelt, A.; Allan, E.; Beßler, H.; Bonkowski, M.; Buchmann, N.; Buscot, F.; Clement, L. W.; Ebeling, A.; Engels, C.; Halle, S.; Kertscher, I.; Klein, A.-M.; Koller, R.; König, S.; Kowalski, E.; Kummer, V.; Kuu, A.; Lange, M.; Lauterbach, D.; Middelhoff, C.; Migunova, V. D.; Milcu, A.; Müller, R.; Partsch, S.; Petermann, J. S.; Renker, C.; Rottstock, T.; Sabais, A.; Scheu, S.; Schumacher, J.; Temperton, V. M.; Tscharntke, T. Bottomup effects of plant diversity on multitrophic interactions in a biodiversity experiment. Nature 2010, 468, 553-556.

(49) Qian, H.; Ricklefs, R. E. Global concordance in diversity patterns of vascular plants and terrestrial vertebrates. Ecology Letters 2008, 11, 547-553.

(50) Seabloom, E. W.; Kinkel, L.; Borer, E. T.; Hautier, Y.; Montgomery, R. A.; Tilman, D. Food webs obscure the strength of plant diversity effects on primary productivity. Ecol Lett. 2017, 20, $505-512$.

(51) Westgate, M. J.; Barton, P. S.; Lane, P. W.; Lindenmayer, D. B. Global meta-analysis reveals low consistency of biodiversity congruence relationships. Nat. Commun. 2014, 5, 3899.

(52) Verheijen, L. M.; Aerts, R.; Bönisch, G.; Kattge, J.; van Bodegom, P. M. Variation in trait trade-offs allows differentiation among predefined plant functional types: Implications for predictive ecology. New Phytol. 2016, 209, 563-575.

(53) Lefcheck, J. S.; Bastazini, V. A. G.; Griffin, J. N. Choosing and using multiple traits in functional diversity research. Environ. Conserv. 2015, 42, 104-107.

(54) Legras, G.; Loiseau, N.; Gaertner, J.-C.; Poggiale, J.-C.; Gaertner-Mazouni, N. Assessing functional diversity: The influence of the number of the functional traits. Theoretical Ecology [Online early access]. 202013117.
(55) Laughlin, D. C. The intrinsic dimensionality of plant traits and its relevance to community assembly. J. Ecol. 2014, 102, 186-193.

(56) Iversen, C. M.; McCormack, M. L.; Powell, A. S.; Blackwood, C. B.; Freschet, G. T.; Kattge, J.; Roumet, C.; Stover, D. B.; Soudzilovskaia, N. A.; Valverde-Barrantes, O. J.; van Bodegom, P. M.; Violle, C. A global Fine-Root Ecology Database to address belowground challenges in plant ecology. New Phytol. 2017, 215, 15-26.

(57) Maire, E.; Grenouillet, G.; Brosse, S.; Villéger, S. How many dimensions are needed to accurately assess functional diversity? A pragmatic approach for assessing the quality of functional spaces. Global Ecology and Biogeography 2015, 24, 728-740.

(58) Schleuter, D.; Daufresne, M.; Massol, F.; Argillier, C. A user's guide to functional diversity indices. Ecol. Monogr. 2010, 80, 469484.

(59) Bare, J. C.; Hofstetter, P.; Pennington, D. W.; de Haes, H. A. U. Midpoints versus endpoints: The sacrifices and benefits. Int. J. Life Cycle Assess. 2000, 5, 319.

(60) Verones, F.; Huijbregts, M. A. J.; Chaudhary, A.; de Baan, L.; Koellner, T.; Hellweg, S. Harmonizing the Assessment of Biodiversity Effects from Land and Water Use within LCA. Environ. Sci. Technol. 2015, 49, 3584-3592.

(61) Wang, J.-J.; Jing, Y.-Y.; Zhang, C.-F.; Zhao, J.-H. Review on multi-criteria decision analysis aid in sustainable energy decisionmaking. Renewable Sustainable Energy Rev. 2009, 13, 2263-2278.

(62) Prado-Lopez, V.; Seager, T. P.; Chester, M.; Laurin, L.; Bernardo, M.; Tylock, S. Stochastic multi-attribute analysis (SMAA) as an interpretation method for comparative life-cycle assessment (LCA). Int. J. Life Cycle Assess. 2014, 19, 405-416.

(63) Kissling, W. D.; Walls, R.; Bowser, A.; Jones, M. O.; Kattge, J.; Agosti, D.; Amengual, J.; Basset, A.; van Bodegom, P. M.; Cornelissen, J. H. C.; Denny, E. G.; Deudero, S.; Egloff, W.; Elmendorf, S. C.; Alonso García, E.; Jones, K. D.; Jones, O. R.; Lavorel, S.; Lear, D.; Navarro, L. M.; Pawar, S.; Pirzl, R.; Rüger, N.; Sal, S.; SalgueroGómez, R.; Schigel, D.; Schulz, K.-S.; Skidmore, A.; Guralnick, R. P. Towards global data products of Essential Biodiversity Variables on species traits. Nature Ecology \& Evolution 2018, 2, 1531-1540. 